\title{
7-Hydroxymatairesinol improves body weight, fat and sugar metabolism in C57BJ/6 mice on a high-fat diet
}

\author{
Giorgio Biasiotto ${ }^{1,2} \dagger$, Isabella Zanella ${ }^{1,2} \dagger$, Federica Predolini ${ }^{1,2}$, Ivonne Archetti ${ }^{3}$, Moris Cadei $^{4}$, \\ Eugenio Monti ${ }^{2}$, Marcello Luzzani ${ }^{5}$, Barbara Pacchetti ${ }^{5}$, Paola Mozzoni ${ }^{6}$, Roberta Andreoli ${ }^{6}$, \\ Giuseppe De Palma ${ }^{7}$, Federico Serana ${ }^{1}$, Annika Smeds ${ }^{8}$ and Diego Di Lorenzo ${ }^{1 *}$ \\ ${ }^{1}$ Clinical Chemistry Laboratory, Diagnostic Department, ASST Spedali Civili di Brescia, P. Le Spedali Civili 1, 25123 Brescia, \\ Italy \\ ${ }^{2}$ Department of Molecular and Translational Medicine, University of Brescia, Via Valsabbina 1, 25123 Brescia, Italy \\ ${ }^{3}$ Istituto Zooprofilattico Sperimentale della Lombardia e dell'Emilia Romagna (IZSLER), "Bruno Ubertini", Via Bianchi, 9 , \\ 25124 Brescia, Italy \\ ${ }^{4}$ Human Pathology, School of Medicine, University of Brescia, P. Le Spedali Civili 1, 25123 Brescia, Italy \\ ${ }^{5}$ Linnea SA, via Cantonale 123, CH-6595 Riazzino, Switzerland \\ ${ }^{6}$ Laboratory of Industrial Toxicology, Department of Medicine and Surgery, University of Parma, 43126 Parma, Italy \\ ${ }^{7}$ Department of Medical and Surgical Specialties, Radiological Sciences and Public Health, Section of Public Health and \\ Human Sciences, University of Brescia, P. Le Spedali Civili 1, 25123 Brescia, Italy \\ ${ }^{8}$ Laboratory of Wood and Paper Chemistry, Abo Akademi University, 20500 Turku, Finland
}

(Submitted 18 December 2017 - Final revision received 30 April 2018 - Accepted 15 May 2018 - First published online 14 August 2018)

\begin{abstract}
7-Hydroxymatairesinol (7-HMR) is a plant lignan abundant in various concentrations in plant foods. The objective of this study was to test HMRLignan $^{\mathrm{TM}}$, a purified form of 7-HMR, and the corresponding Picea abies extract (total extract $P$. abies; TEP) as dietary supplements on a background of a high-fat diet (HFD)-induced metabolic syndrome in mice and in the 3T3-L1 adipogenesis model. Mice, 3 weeks old, were fed a HFD for $60 \mathrm{~d}$. Subgroups were treated with $3 \mathrm{mg} / \mathrm{kg}$ body weight 7 -HMR (HMRLignan ${ }^{\mathrm{TM}}$ ) or $10 \mathrm{mg} / \mathrm{kg}$ body weight TEP by oral administration. 7-HMR and TEP limited the increase in body weight ( -11 and $-13 \%)$ and fat mass $(-11$ and $-18 \%)$ in the HFD-fed mice. Epididymal adipocytes were 19 and $-12 \%$ smaller and the liver was less steatotic (-62 and $-65 \%)$. Serum lipids decreased in TEP-treated mice ( $-11 \%$ cholesterol, $-23 \%$ LDL and $-15 \%$ TAG) and sugar metabolism was ameliorated by both lignan preparations, as shown by a more than $70 \%$ decrease in insulin secretion and insulin resistance. The expression of several metabolic genes was modulated by the HFD with an effect that was reversed by lignan. In 3T3-L1 cells, the 7-HMR metabolites enterolactone (ENL) and enterodiol (END) showed a $40 \%$ inhibition of cell differentiation accompanied by the inhibited expression of the adipogenic genes $P P A R \gamma, C / E B P \alpha$ and $a P 2$. Furthermore, END and ENL caused a $10 \%$ reduction in TAG uptake in HEPA 1-6 hepatoma cells. In conclusion, 7-HMR and TEP reduce metabolic imbalances typical of the metabolic syndrome and obesity in male mice, whereas their metabolites inhibit adipogenesis and lipid uptake in vitro.
\end{abstract}

Key words: Lignan: 7-Hydroxymatairesinol: Obesity: Adipose deposition: Adipocyte differentiation: Metabolism

The high prevalence of the metabolic syndrome and excessive adipose tissue accumulation (in particular, abdominal obesity) is a major threat to public health, being associated with a substantial decrease in health-related quality of life and an increase in economic costs ${ }^{(1-3)}$. Thus, new strategies related to the long-term prevention and reduction of incidence and severity of CVD and type 2 diabetes need to be initiated. Among these is the identification of beneficial bioactive compounds within many foods, as appropriate dietary strategies that may themselves positively affect disease predisposition and evolution ${ }^{(4)}$.

Lignans are chemicals produced as secondary metabolites ${ }^{(5,6)}$. They occur in the whole plant kingdom and can also be found in fibre-rich foods and particularly concentrated in oilseeds (especially in flaxseed and sesame) ${ }^{(7-9)}$, in cereal grains (e.g. wheat and rye bran), nuts ${ }^{(10)}$, Brassica species, legumes, berries and in many plant-related beverages (tea,

Abbreviations: 7-HMR, 7-hydroxymatairesinol; DMSO, dimethylsulfoxide; END, enterodiol; ENL, enterolactone; HFD, high-fat diet; LFD, low-fat diet; PA, palmitic acid; TEP, total Picea abies extract; TFEB, transcription factor EB.

* Corresponding author: D. Di Lorenzo, email diego.dilorenzo@yahoo.it

$\dagger$ These authors contributed equally to this work. 
coffee and so on $)^{(11)}$. 7-Hydroxymatairesinol (7-HMR) is a dibenzylbutyrolactone plant lignan closely related to matairesinol. It is found at relatively high concentrations in the heartwood of branches and knots of Norway spruce trees (Picea abies) ${ }^{(12)}$ and in various concentrations in plant foods ${ }^{(10-14)}$. The activity and metabolism of 7-HMR has been recently evaluated in rats and in humans, with enterolactone (ENL) being the major metabolite identified ${ }^{(15,16)}$. Other metabolites detected included hydroxyenterolactone, $\alpha$-conidendrin, conidendric acid, enterodiol (END), allo-7-HMR and unchanged 7-HMR. All of these minor metabolites, including unchanged 7-HMR, were at concentrations many-fold lower than the primary metabolite $\mathrm{ENL}^{(15)}$.

In contrast to other well-studied lignans, which are highly concentrated in oilseeds such as sesamin or secoisolariciresinol $^{(17,18)}, 7$-HMR, although also present in oilseeds, was only recently detected in several cereals by applying improved extraction and detection methodologies ${ }^{(10)}$. 7 -HMR is found to be concentrated in rye, wheat, triticale, oat, barley, millet, maize bran and amaranth whole grain ${ }^{(10)}$. Thus, as these grains are widely consumed worldwide in various forms, we intended to study 7-HMR, which is the dominant lignan in these foods, in a model of the metabolic syndrome ${ }^{(19)}$ for which the metabolic functions and effects of 7-HMR are still elusive.

In this work, we investigate the effect of 7-HMR on the pathological alterations that occur with the metabolic syndrome following a high-fat diet (HFD), at a dose suggested for nutraceutical use (HMRLignan ${ }^{\mathrm{TM}}$ ) (which provides a high intake of this compound), but that can also produce levels of mammalian metabolites (ENL and END) similar to those reached with a lignan-rich diet.

\section{Methods}

\section{Chemicals}

7-HMR potassium acetate complex (HMRLignan ${ }^{\mathrm{TM}}$ ) was prepared by co-crystallisation of $P$. abies extract and potassium acetate in a ternary solvent system (ethanol, ethylacetate, water), as previously described $^{(10)}$. The purity of the preparation HMRLignan ${ }^{\mathrm{TM}}$ batch 12809003 is as follows: hydroxymatairesinol potassium acetate $99 \%$ and related substance $4 \%$. Total $P$. abies extract (TPE) is a mixture of 7-HMR and allo-hydroxymatairesinol, produced by hot ethanolic extraction of $P$. abies knots. TEP is an intermediate in the process to obtain pure 7-HMR. All steps in the 7-HMR purification process are validated, and thus TEP is a standardised and replicable product. The product contains $31 \%$ 7-HMR, 16\% allo-hydroxymatairesinol and other natural constituents of the herbal drug. The balance to $100 \%$ is potassium acetate and water. The chemicals were dissolved in dimethylsulfoxide (DMSO) and further diluted before their oral administration to the mice or the treatment of the cells. The chemicals (HMRLignan ${ }^{\mathrm{TM}}$ and TEP) for the experiments were provided by Linnea SA free of charge. The complete chemical analysis of 7HMR is freely available upon request to the corresponding author. In this work, we use the name 7-HMR throughout the text. HMRLignan $^{\mathrm{TM}}$ is the proprietary name of the commercial preparation. Palmitic acid (PA; Sigma-Aldrich) was dissolved in isopropylic alcohol at a 100-mm stock concentration. Stock solution was diluted to $1.25 \mathrm{~mm}$ in warm Dulbecco's modified Eagle's medium (DMEM) containing 10\% fetal bovine serum (FBS; Gibco) and $10 \%$ bovine serum albumin (BSA; Sigma-Aldrich). The 1.25-mm solution was further diluted in warm growth medium at a final concentration of $125 \mu \mathrm{m}$ to treat cells. The END and ENL enterolignans were purchased from Sigma-Aldrich and dissolved in DMSO at a stock concentration of $10 \mathrm{~mm}$ and further diluted in DMSO for experiments with cells.

\section{Experimental animals}

The procedures involving animals and their care were conducted in accordance with institutional guidelines, which comply with national and international laws and policies (National Institutes of Health, Guide for the Care and Use of Laboratory Animals, 1996 (7th ed.) (Washington, DC); National Academies Press, National Research Council Guide, www.nap.edu/readingroom/ books/labrats). C57BJ/6 mice (Harlan, Udine) were kept in animal rooms maintained at a temperature of $23^{\circ} \mathrm{C}$, with natural light/dark cycles in aerated $(40 \times 25 \mathrm{~cm})$ polycarbonate cages at a density of 8 mice/cage. Chemicals were administered by oral administration in $100 \mu$ l of vegetable oil at 10.00 hours with disposable flexible polypropylene tubes in plastic with a soft bulb tip to minimise tissue damage. At the end of the treatments, the animals were killed by cervical dislocation after having received diethyl ether anaesthesia, and the tissues were dissected and immediately frozen on dry ice. Serum was separated from blood cells by centrifugation at $18928 \mathrm{G}$-force (13000 rpm).

Food consumption was monitored every $2 \mathrm{~d}$ as the difference between the weight of the supplied and the consumed pellets. Spilled food, if any, was collected in apposite trays underneath the food containers, measured and taken into account.

\section{Diets}

Low-fat diet (LFD) and HFD containing 10 and 50\% energy content from fat, respectively, were purchased from Piccioni (www.totofood.it/). The diet was prepared in pellets. The composition is reported in Table 1. Assay of 7-HMR or TEP or analogues in the diets did not reveal any presence of these

Table 1. Composition of the diets*

\begin{tabular}{ll}
\hline $\begin{array}{l}\text { LFD (10\% energy content } \\
\text { from fat) }\end{array}$ & HFD (50\% energy content from fat) \\
\hline $20 \%$ casein & $25 \%$ casein \\
$0.3 \%$ L-cystine & $0.3 \%$ cystine \\
$25 \%$ maize starch & $10.8 \%$ maize starch \\
$8.5 \%$ maltodextrin & $5.0 \%$ maltodextrin \\
$31.5 \%$ sucrose & $20.5 \%$ sucrose \\
$5.0 \%$ cellulose & $5.0 \%$ cellulose \\
$2.5 \%$ maize oil & $2.5 \%$ maize oil \\
$2.0 \%$ lard & $13.0 \%$ lard plus $12.5 \%$ hydrogenated \\
& coconut oil \\
$4.0 \%$ mineral mix & $4.0 \%$ mineral mix \\
$1.0 \%$ vitamin mix & $1.0 \%$ vitamin mix \\
$0.2 \%$ choline bitartrate & $0.4 \%$ choline chloride
\end{tabular}

LFD, low-fat diet; HFD, high-fat diet.

* Amounts of components in the diets: LFD and HFD containing 10 and $50 \%$ fat, respectively, were purchased from Piccioni. 
chemicals. Quantification was performed by the method reported in Smeds et $a l .^{(10,20,21)}$. Food consumption was monitored every $2 \mathrm{~d}$ as difference between the weight of the furnished and the consumed pellets (see the 'Results' section). Mean daily water intake was $3.5(\mathrm{se} 0.2) \mathrm{ml} /$ mouse for mice on the LFD and 3.8 ( $\mathrm{sE}$ $0 \cdot 4) \mathrm{ml} / \mathrm{mouse}$ for mice on the HFD. 7-HMR or TEP administration did not change the average water intake.

The LFD was composed of $15.6 \%$ SFA, $45 \cdot 2 \%$ MUFA and $39.2 \%$ PUFA, whereas the HFD was composed of $60.3 \%$ SFA, $32.9 \%$ MUFA and $6.7 \%$ PUFA.

\section{Echo MRI analysis}

The Echo MRI system (EchoMRI Corporation Pte Ltd) was used as already reported ${ }^{(22)}$.

\section{Determination of 7-hydroxymatairesinol and metabolites in mouse serum}

7-HMR, END and ENL were determined by HPLC-MS/MS in the mouse serum samples after enzymatic hydrolysis and solid-phase extraction according to a previously described method ${ }^{(20)}$. The method was slightly modified by taking $50 \mu$ of serum instead of $600 \mu \mathrm{l}$ and 290 units of $\beta$-glucuronidase/sulphatase dissolved in $0.5 \mathrm{ml}$ of $10 \mathrm{~mm}$ sodium acetate buffer $(\mathrm{pH} 5.0)$ for each sample (for the enzymatic hydrolysis). The glucuronidase used was $\beta$-glucuronidase/sulphatase (type $\mathrm{H}-1$, from Helix pomatia) (Sigma-Aldrich Co.). The samples were incubated at $37^{\circ} \mathrm{C}$ for $19 \mathrm{~h}$ and cleaned after incubation by solid-phase extraction. For details, see Smeds et $a l^{(21)}$. The possible presence of residual lignans in the glucuronidase preparation was not determined, as the method has been validated and found reliable. The small amounts of ENL and END measured in mice on the LFD and HFD reflect the consumption of a certain amount of sawdust as no other sources of lignans were used in this work.

\section{Biochemical assays}

Blood was collected from each mouse, stored at $37^{\circ} \mathrm{C}$ for $30 \mathrm{~min}$ and centrifuged at $3500 \mathbf{g}$ at room temperature for $10 \mathrm{~min}$ to obtain serum. TAG, HDL and cholesterol concentrations were measured spectrophotometrically with a biochemical multianalyser ILab Aries (Instrumentation Laboratory Company) using kits by the same manufacturer. The parameters are as follows: TAG analytical range, $0.07-11.3 \mathrm{mmol} / \mathrm{l}$; precision, CV (\%) 1.5; cholesterol analytic range, $0 \cdot 1-23.3 \mathrm{mmol} / 1$; precision, CV (\%) 2.0; HDL-cholesterol analytic range, 0.03-6.5 mmol/1; precision, CV (\%) 3.1. Species-specific kits are not necessary for the determination of these parameters. Our value ranges are in agreement with data from the literature on the same analytes. Insulin concentration was assayed by a standardised mouse insulin assay (catalogue no. EZRMI-13K; Millipore) and insulin sensitivity was determined by the homoeostasis model assessment (Diabetes Trials Unit, The Oxford Centre for Diabetes). The oral glucose tolerance test was performed as previously described $^{(22)}$. Mice were deprived of food overnight and then orally given glucose $(1 \mathrm{mg} / \mathrm{g}$ body weight). Tail vein blood samples were taken at $0,15,30,45$ and $60 \mathrm{~min}$ after glucose administration to measure blood glucose concentrations. Blood glucose concentrations were measured by a portable Accucheck compact glucometer (Roche Diagnostic GmbH). AUC was calculated by using the trapezoid rule ${ }^{(23)}$.

For immunoblot analysis, cell lysates were obtained as previously described $^{(23)}$. Equal protein amounts, separated by SDSPAGE, were transferred to polyvinylidene difluoride (PVDF) membranes. Filters were incubated with diluted 1:1000 primary antibodies (mouse anti-PPAR $\mathrm{x}$ and mouse anti-fatty acid binding protein 4, $A P 2 / F A B P 4$ ) and then with peroxidase-labelled goat anti-mouse secondary antibody. All antibodies were purchased from Santa Cruz Biotechnology. Bound activity was revealed by chemiluminescence (SuperSignal West Femto Substrate; Thermo Fisher Scientific). The chemiluminescent signal was captured and quantified by the use of GENEGNOME (Syngene).

\section{RNA extraction and gene expression analysis}

Total RNA was extracted from 10 to $30 \mathrm{mg}$ of tissue or from treated cells using $1 \mathrm{ml}$ of TRIzol Reagent (Thermo Fisher Scientific), according to the manufacturer's instructions. Tissues in TRIzol reagent were pre-homogenised at $30 \mathrm{~Hz}$ for 3 min using the homogeniser MM301 (Qiagen). RNA for each sample was treated with RQ1-DNaseI (Promega) and reversed-transcribed using Improm II Reverse Transcriptase (Promega) and random hexamer primers. For quantitative RT-PCR, $2 \mu \mathrm{l}$ of single-stranded complementary DNA was mixed with TaqMan Universal PCR Master (Thermo Fisher Scientific) and assay-ondemand gene-specific products, using HPRT1 as the normalising gene (Integrated DNA Technology), and analysed on a ABI PRISM 7700 Sequence Detection System (Life Technologies). The calculation of threshold cycle $\left(C_{t}\right)$ values was performed using the SDS 2.2 software (Applied Biosystems), after automatically setting the baseline and the threshold. Data were analysed using the $2^{-\Delta \Delta C_{t}}$ method, as previously described ${ }^{(24)}$.

\section{Histological examination}

Epididymal adipose tissue and liver were fixed in formaldehyde and embedded in paraffin. Sections measuring $3 \mu \mathrm{m}$ were dewaxed and rehydrated through decreasing alcohol series up to distilled water and stained with haematoxylin-eosin. Original magnification was $20 \times$. Analyses were conducted in a blinded manner by two independent pathologists.

Cell culture and treatments. Mouse 3T3-L1 confluent cells (cells with a fibroblast-like morphology, differentiating into an adipocyte-like phenotype) were cultured in basal or differentiation medium (3-isobutyl-1-methylxanthine, dexamethasone, insulin; MDI) as described ${ }^{(22,25)}$. On day 9 after induction of differentiation, the cells were treated with different doses of 7-HMR, TEP, ENL and END $(0 \cdot 01,0 \cdot 1,1 \mu \mathrm{M})$ for two further days. On day 9 after differentiation induction, lipid content was quantified as described $^{(22)}$. For mRNA quantification the confluent cells were treated for $48 \mathrm{~h}$ with vehicle or defined concentrations of the molecules, and RNA was extracted using the TriReagent Solution (Ambion), treated with DNaseI (Promega) and reverse- 
transcribed. Quantitative PCR analyses were performed using Assay on Demand kits on an ABI PRISM 7000 (Applied Biosystems) ${ }^{(26)}$. HPRT1 was used as the reference gene.

Murine HEPA 1-6 hepatocarcinoma cells (IZSLER Brescia) were used as the steatosis in vitro model. Cells were cultured in DMEM medium containing $10 \%$ FBS. For PA treatment, cells were seeded at a density of $2 \times 10^{4} /$ well in ninety-six-well plates in growth medium for $24 \mathrm{~h}$. Then, medium containing the SFA PA at $125 \mu \mathrm{m}$ was applied for $24 \mathrm{~h}$ in the presence of vehicle (isopropylic alcohol $0 \cdot 1 \%$, plus BSA $1 \%$, plus DMSO $0 \cdot 05 \%$ ) or 7 HMR, TEP, END or ENL in the dose range of $0 \cdot 001-1 \mu \mathrm{M}$.

\section{Statistical analysis}

Sample size was calculated in order to be able to detect differences of about $5 \mathrm{~g}$ in total body weight between HFD mice using one-way repeated-measures ANOVA at $80 \%$ power. Calculations were performed using the G*Power 3.1.5 software (available at http://www.gpower.hhu.de/en.html). With a $\beta$ level of $0 \cdot 20$, an $\alpha$ level of 0.05 and a small effect size, the sample size was thirty-nine mice in each of the four groups (then increased to forty, to account for possible dropouts). Statistical analysis was performed by ANOVA, either one-way or two-way with repeated measures on one factor, according to the data type, followed by post hoc Bonferroni analysis. All the analyses were conducted in a blinded manner and were performed using the Prism 5.0 software (GraphPad Software, www.graphpad.com).

\section{Results}

\section{Effects of 7-hydroxymatairesinol and total Picea abies} extract on body fat deposition, lipid profile and sugar metabolism in male mice fed a high-fat diet

Peripubertal male mice, 3 weeks old, were randomised into four groups (LFD, HFD, HFD + 7-HMR and HFD + TEP). The compounds were given daily by oral administration to mimic dietary assumption and to allow microbiota metabolism. The mice were fed the LFD or the HFD plus or minus the oral lignan for $60 \mathrm{~d}$. Average food consumption was 2.99 (SE 0.5) g/mouse per $\mathrm{d}$ for the mice on the LFD $(46.65 \mathrm{~kJ} /$ mouse per $\mathrm{d}(11.15 \mathrm{kcal} /$ mouse per d) and $2 \cdot 61$ (SE 0.4$) \mathrm{g} /$ mouse per $\mathrm{d}$ for the mice on the HFD $(51.46 \mathrm{~kJ} /$ mouse per d $(12.30 \mathrm{kcal} /$ mouse per $\mathrm{d}))$. Food intake of the mice on the HFD plus oral administration with vegetable oil with dissolved 7-HMR or TEP was 2.70 (SE 0.6) g/ mouse per $\mathrm{d}$ and 2.65 (SE 0.6 ) g/mouse per d, respectively, showing that vegetable oil plus the chemicals did not have any effect compared with vegetable oil alone.

HFD-fed mice were treated daily with $3 \mathrm{mg} / \mathrm{kg}$ body weight (bw) 7-HMR (doses of 1 up to $22.5 \mathrm{mg} / \mathrm{kg}$ body weight have been studied in humans and showed no toxic effects) ${ }^{(16)}$ (HORMOS study number: 3000-4302 and one manuscript in preparation) or $10 \mathrm{mg} / \mathrm{kg}$ body weight TEP (an experimental dose based on previous unpublished results). Total body weight was measured periodically for $60 \mathrm{~d}$ and total body fat was measured at the end of the experiment. From day 30 until the end of the experiment the body weight started to be significantly lower in mice treated with
7-HMR and TEP ( -7 and $-6 \%$, respectively, at day 30 , and -11 and $-13 \%$, respectively, at day 60) compared with the mice on the HFD alone (Fig. 1(a)).

We also found that total fat and isolated epididymal and gluteal fat pads were significantly smaller in the 7-HMR- and TEP-treated mice compared with mice on the HFD alone (Fig. 1(b)-(d)). Serum glycaemia decreased (fasting glucose: $-12 \% 7-\mathrm{HMR}$ and $-14 \%$ TEP. AUC -33\% 7-HMR and -27\% TEP), as well as insulin secretion $(-74 \% 7-\mathrm{HMR}$ and $-89 \% \mathrm{TEP})$ and insulin resistance (-71\% 7-HMR and -78\% TEP), in the 7-HMR- and TEP-treated mice (Fig. 2(a)-(e)). Histological examination of the adipocyte size in epididymal fat revealed that the decrease in fat weight of mice fed 7-HMR or TEP corresponds to a decrease in cellular dimensions (Fig. 3(a) and (b)). Mice on the HFD developed accumulation of lipid droplets in the liver (liver steatosis), which were measured by histological analysis (Fig. 3(c)) and the fat content quantified (Fig. 3(d)). 7-HMR and TEP lowered the lipid content in the liver of the treated mice.

Effects of 7-hydroxymatairesinol and total Picea abies extract on serum lipids profile in male mice fed a high-fat diet

After 10 weeks on the HFD, we observed a decrease in total serum cholesterol levels $(-11 \%)$ in TAG $(-15 \%)$ and LDL $(-23 \%)$ in mice fed the TEP-supplemented diets compared with those in HFD-fed mice. HDL did not change in both groups of treated mice (Table 2). No significant changes were visible in the serum of mice fed the 7-HMR-supplemented diet $(P<0.05)$.

\section{Concentration of enterolactone and enterodiol in mouse serum}

The major 7-HMR metabolites ENL and END (Fig. 4), produced by the intestinal microbiota from the dietary precursor, were measured in mouse serum. The sera of mice treated with 7-HMR have significantly higher levels of both metabolites, whereas TEP generated only significant levels of ENL (Table 3), according to a previous work performed in rats with the same precursor ${ }^{(15)}$. The small amount of metabolites measured in mice on the control LFD and HFD reflects the consumption of a certain amount of sawdust as no lignans were detectable in the administered diets.

\section{Changes in metabolic pathways in the visceral fat and the liver}

Increased adipose accumulation is associated with changes in several metabolic parameters in visceral fat and in the liver. We analysed the deregulation of the expression of sets of genes involved in fat accumulation and metabolism, autophagy, inflammation and antioxidant defences.

The genes that were found to be modulated code for members of the inflammatory response pathway. TNF- $\alpha$ and ILC were induced by the HFD and inhibited by 7-HMR and TEP. The antioxidant defence enzyme glutathione-S-transferase 1 was inhibited in the high-fat-treated mice and established at higher levels by TEP. The transcription factor EB (TFEB) was inhibited in the high-fat group and was re-expressed in 7-HMR and TEPtreated mice. The fat metabolism genes $L P L, P L A 2 G 7$ and leptin 
(a)

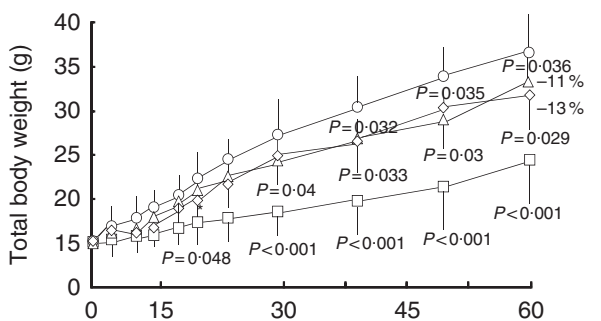

(d)

(c)

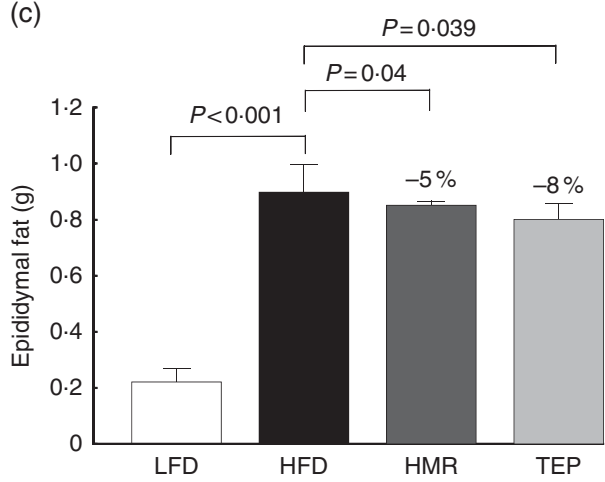

(b)

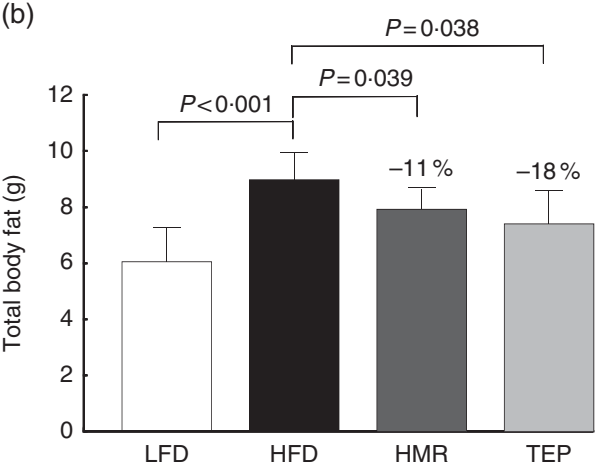

(d)

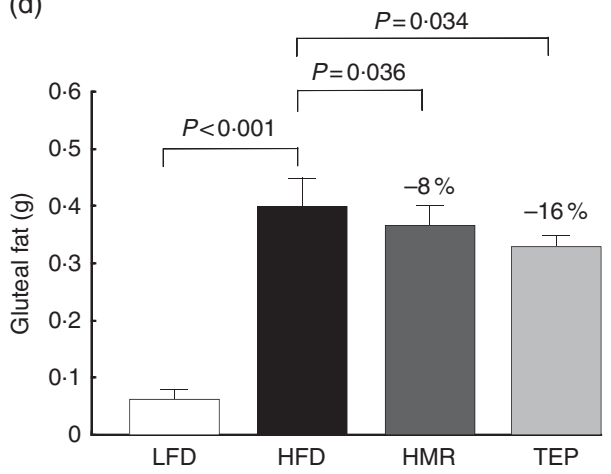

Fig. 1. Effect of 7-hydroxymatairesinol (7-HMR)- and total Picea abies extract (TEP)-medicated diets on fat development in male mice. Time-course effects of control - low-fat diet (LFD), control - high-fat diet (HFD), HFD + 7-HMR and HFD + TEP on body weight and total adipose tissue deposition in male C57BL/6J mice. Total adipose mass was analysed using an EchoMRI system. (a) Total body weight, (b) total body fat (g), (c) weight of epididymal fat and (d) weight of gluteal fat. Time of treatments was $60 \mathrm{~d}$. Fat pads were excised immediately after euthanasia. a: $\square$, LFD; $\bigcirc$, HFD; $\triangle$, HFD + 7-HMR; $\diamond$, HFD + TEP. Percentage values (11 and $13 \%$ less weight) in the graph represent the extent of the change on the HFD value. (b)-(d): $\square$, LFD;, HFD; $\square$, HFD + 7-HMR; $\square$, HFD + TEP at the end of the 60-d treatments $(b-d)$. Percentage values on the histograms represent the extent of the change on the HFD value. Values are means ( $n 40$ per group), with their standard errors represented by vertical bars. $P=$ actual value or $P<0.001$.

were induced by the HFD and repressed by 7-HMR and TEP; the $A T G L$ and adiponectin genes were inhibited by the HFD and restored by TEP (Fig. 5). The PPAR 1 gene, $C / E B P \alpha$ and $a P 2$, which are key factors in adipocyte differentiation and fat metabolism, were up-regulated in both fat and liver and were significantly reduced in TEP-treated mice.

\section{Activity of 7-hydroxymatairesinol and total Picea abies extract on 3T3-L1 cell differentiation and regulation of the PPAR pathway}

To understand whether the increase in fat accumulation observed in vivo could be similarly replicated in vitro and to verify whether it was dependent on fat cell accumulation, we challenged the 3T3-L1 in vitro model of cell differentiation with our compounds. We first characterised the effects of 7-HMR, TEP and the major metabolites ENL and END on 3T3L1 fat cell accumulation. This was performed in cells maintained in differentiation medium and treated with different doses of 7-HMR, TEP, ENL and END (0·01, 0·1, $1 \mu \mathrm{M})$. The OilRed-O staining of the treated cells revealed that the lignan metabolites ENL and END inhibited lipid accumulation in differentiating cells. 7-HMR showed less potency and TEP was not active (Fig. 6). To understand whether the modulation of adipogenesis was occurring at a molecular level through key adipogenic factors, we studied the regulation of $P P A R \gamma$, $C / E B P \alpha$ and $a P 2$ from an array of genes induced in differentiating 3T3-L1 cells (Fig 7(a)). PPARy and $a P 2$ were maximally expressed at day 9 of the differentiation schedule (Fig. 7(b) and (b1)), and thus for the following experiment we used this end point. At day 9 the lignans 7-HMR and ENL inhibited the activity of $P P A R \gamma$, whereas all four lignans efficiently inhibited $C / E B P \alpha$ and $a P 2$ in differentiating cells. The $a P 2$ protein was slightly inhibited in the 7-HMR- and TEP-treated cells (Fig. 8(c)).

\section{Quantification of TAG accumulation in HEPA 1-6 hepatocytes}

In the treated mice, the liver appeared to be responsive to lignan through the inhibition of the diet-induced steatosis, and thus we used a model of liver steatosis in vitro, the HEPA 1-6 hepatoma cells, to identify direct mechanisms of action of the lignans. The cells were challenged with the SFA PA for $24 \mathrm{~h}$ and the accumulated lipids were measured by the Oil-Red-O assay. Fig. 8 shows that TAG content was significantly higher in PA-treated cells. The addition of ENL and END decreased PA-induced TAG accumulation starting at the concentration of $0.001 \mu \mathrm{M}$, whereas 7 -HMR and TEP were effective only at supraphysiological doses $(10 \mu \mathrm{M})$ (not shown). 

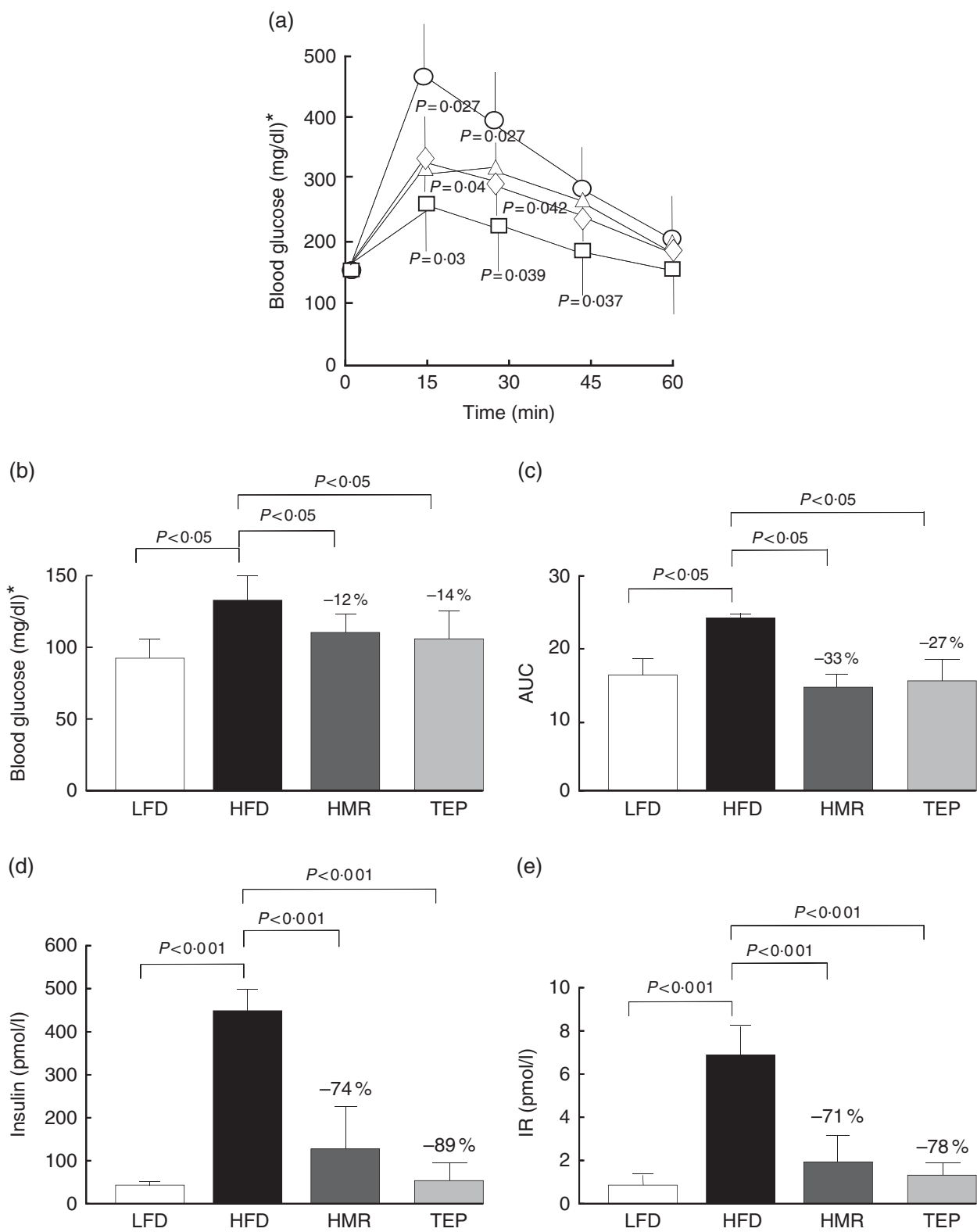

Fig. 2. Glucose tolerance. For glucose tolerance tests animals were fasted overnight for $12 \mathrm{~h}$ and blood samples were obtained from the tail vein. (a) Animals were then injected intraperitoneally with $2 \mathrm{~g} / \mathrm{kg}$ body weight of glucose and blood samples were taken at the indicated intervals. (b) Fasting glucose levels, (c) the AUC (AUC from the glucose tolerance test) and (d) plasma insulin levels were measured with an insulin ELISA kit (Millipore, mouse insulin ninety-six-well plate assay; catalogue no. EZRMI-13K). (e) Determination of homoeostasis model assessment of insulin resistance (IR). Calculations were carried out using glucose and insulin concentrations obtained after $6 \mathrm{~h}$ of food withdrawal, using the HOMA Calculator (Diabetes Trials Unit), the Oxford Centre for Diabetes, Endocrinology and Metabolism: homa.calculator@dtu.ox.ac.uk. a: low-fat diet ( $\square$, control - low-fat diet (LFD); O, control-high-fat diet (HFD); $\diamond$, HFD + 7-hydroxymatairesinol (7-HMR); $\triangle$, HFD + total Picea abies extract (TEP); (b)-(e): $\square$, LFD; $\square$, HFD; $\square$, HFD + 7-HMR; $\square$, HFD + TEP. Percentage values on the histograms represent the extent of the change on the HFD value. Values are means ( $n 10$ per group), with their standard errors represented by vertical bars. $P=$ actual value or $P<0.001$. ${ }^{*}$ To convert glucose in $\mathrm{mg} / \mathrm{dl}$ to $\mathrm{mmol} / \mathrm{l}$, multiply by 0.0555 .

\section{Discussion}

Lignans are expected to have beneficial effects in humans after fermentative conversion in the colon to bioactive metabolites that may favourably influence parameters related to the metabolic syndrome $^{(27)}$. Here we studied the effects of 7-HMR and TEP (a mixture of 7-HMR and allo-HMR) from $P$. abies as anti-obesity compounds at doses that can be reached through nutraceutical supplementation or approached with a lignan-rich diet ${ }^{(28)}$. The study was performed in $\mathrm{C} 57 \mathrm{BJ} / 6$ mice, which, among the mouse models of obesity, show the best similarities to human obesity ${ }^{(29-32)}$. Moreover, similar amounts of the ENL metabolite are observed in our 7-HMR-treated mice and in people on lignan-rich diets, supporting the use of this rodent model for metabolic studies.

The novelty of our results is the demonstration that 7-HMR and TEP exhibit marked effects in limiting body weight, total fat mass deposition, liver steatosis and serum lipids (total cholesterol, LDL-cholesterol and TAG) in mice on a HFD and improve sugar metabolism controlling blood sugar level, insulin concentration 
(a)

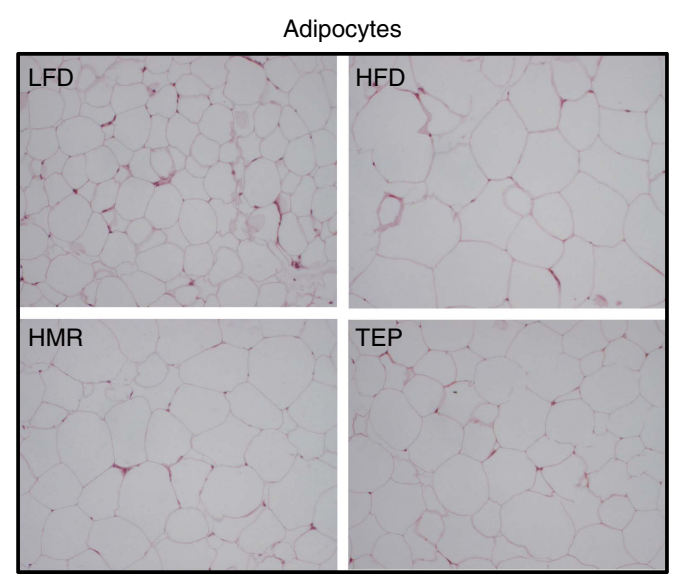

(c)

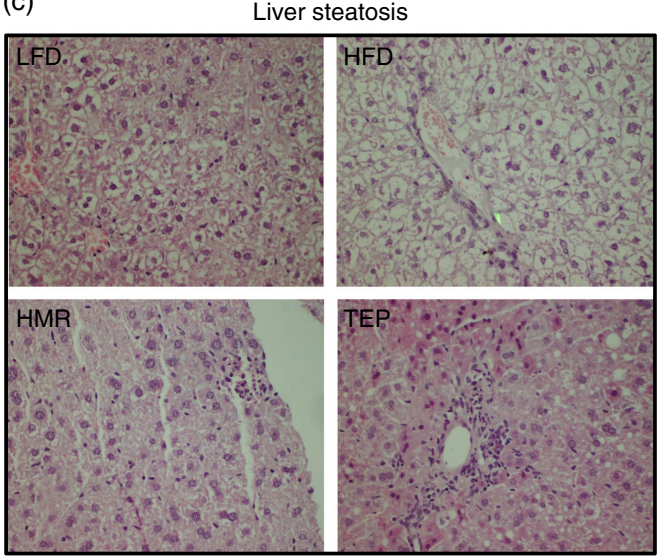

(b)

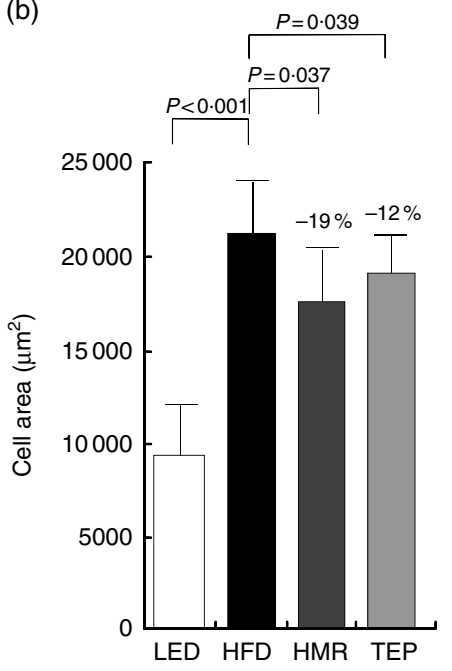

(d)

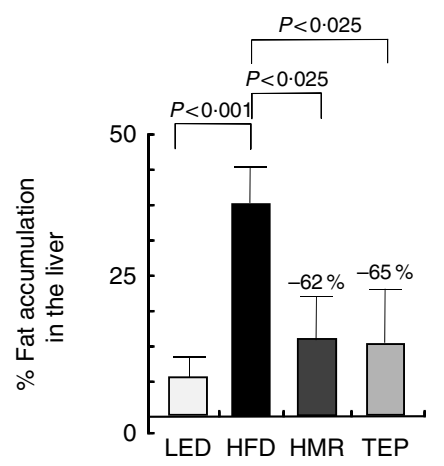

Fig. 3. Histological examination epididymal adipose tissue and liver parenchyma were fixed in formaldehyde and paraffin embedded. Sections $(3 \mu \mathrm{m})$ were stained with haematoxylin-eosin. Cells were photographed at 20x magnification with a digital camera (Nikon Digital Camera DMX 1200). (a, b) Adipocyte size was measured using dedicated software (Image Pro Plus; Imaging and Computer). At least four different fields of three different tissue sections were evaluated for each sample. (c) Liver steatosis. Representative liver sections stained with haematoxylin-eosin. (d) Liver tissue was processed to quantify the fat content. Percentage fat content was determined relative to fat content in the liver of mice on the high-fat diet (HFD). Data represent the average result of the analysis of tissues from five different mice $(n 5)$. Percentage values on the histograms represent the extent of the change on the HFD value. Values are means with their standard errors represented by vertical bars. LFD, low-fat diet; HMR, hydroxymatairesinol; TEP, total Picea abies extract. $P=$ actual value, or $P<0.025$, or $P<0.001$.

Table 2. Lipid profile in serum*

(Mean values and standard deviation; $n 10$ samples/group)

\begin{tabular}{|c|c|c|c|c|c|c|c|c|c|c|}
\hline & \multicolumn{2}{|c|}{ Control (LFD) } & \multicolumn{3}{|c|}{ Control (HFD) (Group a) } & \multicolumn{2}{|c|}{ HFD plus 7-HMR (Group b) } & \multicolumn{3}{|c|}{ HFD plus TEP (Group c) } \\
\hline & Mean & SD & Mean & SD & $P$ & Mean & SD & Mean & SD & $P$ \\
\hline Total cholesterol $(\mathrm{mg} / \mathrm{dll}) \dagger$ & 178 & 28 & 219 & 49 & 0.02 & 208 & 53 & 196 & 37 & 0.01 \\
\hline $\mathrm{LDL}(\mathrm{mg} / \mathrm{dl}) \dagger$ & 37 & 11 & 57 & 23 & 0.02 & 53 & 20 & 43 & 15 & 0.02 \\
\hline $\mathrm{HDL}(\mathrm{mg} / \mathrm{dl}) \dagger$ & 112 & 21 & 133 & 26 & 0.04 & 139 & 35 & 141 & 68 & \\
\hline TAG (mg/dl)† & 118 & 17 & 153 & 36 & 0.03 & 140 & 51 & 129 & 41 & 0.03 \\
\hline
\end{tabular}

LFD, low-fat diet; HFD, high-fat diet; 7-HMR, 7-hydroxymatairesinol; TEP, total Picea abies extract.

* Serum lipids were measured in the different groups of mice. From the left column: control mice on the LFD, mice on the HFD, mice on the HFD plus 7-HMR; mice on the HFD plus TEP. Group a, mice on the HFD $v$. mice on the LFD; group b, 7-HMR-treated mice $v$. mice on the HFD alone; group c, TEP-treated mice $v$. mice on the HFD alone. $P=$ actual value. $\dagger$ To convert cholesterol in $\mathrm{mg} / \mathrm{dl}$ to $\mathrm{mmol} / \mathrm{l}$, multiply by 0.0259 . To convert TAG in $\mathrm{mg} / \mathrm{dl}$ to $\mathrm{mmol} / \mathrm{l}$, multiply by 0.0113 .

and insulin resistance, all strongly altered parameters in the obese mice. The activity of these compounds on metabolic pathways in fat tissue was evidenced at the level of the expression of modulated genes such as $P P A R \gamma$ and $C / E B P \alpha$, which are master regulators of fat metabolism whose activity is critical for progression to the final stages of adipocyte differentiation ${ }^{(33-35)}$. 
In the mouse liver, the fat-rich diet inhibited regulators of lysosomal biogenesis and autophagy pathways such as the master gene TFEB in parallel to an increase in fat accumulation and the induction of severe steatosis, in line with the observations of Settembre et al. ${ }^{(36)}$ who showed that autophagy is required for lipid degradation via the TFEB pathway. 7-HMR and TEP increased TFEB to levels found in the liver of mice on the LFD ( $10 \%$ fat), suggesting that the TFEB-regulated pathway may be one of the mechanisms through which lignan can prevent liver steatosis. Amelioration of liver steatosis was also investigated in vitro by using the HEPA 1-6 model. Both the metabolites ENL and END were effective in limiting fat<smiles>COc1cc(C[C@H]2C(=O)OC[C@@H]2C(O)c2ccc(O)c(OC)c2)ccc1O</smiles>

7-Hydroxymatairesinol<smiles>CCOCCc1cccc(O)c1</smiles><smiles>CCOC(=O)OCCc1cccc(O)c1</smiles><smiles>COc1cc([C@H]2c3cc(O)c(OC)cc3C[C@@H]3C(=O)OC[C@@H]32)ccc1O</smiles>

Fig. 4. Structure of 7-hydroxymatairesinol (7-HMR) and mammalian lignan. The molecular structure of 7-HMR and mammalian metabolites. accumulation experimentally induced in these cells, already at the concentration of $1 \mathrm{~nm}$, whereas 7-HMR and TEP showed no effect, indicating that the inhibition of lipid accumulation in the liver is exerted by these dietary compounds in their metabolised form at concentrations as can be found in human plasma of subjects consuming a lignan-rich $\operatorname{diet}^{(20,21)}$

In the attempt to further delineate mechanisms at fat-cell level, we studied our chemicals in 3T3-L1 cells, a model of adipocyte differentiation. 7-HMR exerted anti-adipogenic effects, although both metabolites ENL and END showed much higher efficiency. At the molecular level, all the lignans effectively inhibited the $C / E B P \alpha$ and $a P 2$ transcription factors, whereas only 7-HMR and ENL modulated PPAR expression, suggesting that inhibition of lipid accumulation may probably involve an indirect control of $P P A R \gamma$ through $C / E B P$ family members. $C / E B P \alpha(C / E B P$ bomologous protein $)$ is a factor that directly or indirectly can affect $P P A R \gamma$ expression, stability and activity and consequently adipogenesis. This can occur through co-activators of the $C / E B P$ family, possibly $C H O P$, a dominant negative form of the $C / E B P$ members ${ }^{(37)}$ that blocks adipogenesis $^{(38)}$ through inhibition of $C / E B P \beta$, which is expressed early in the differentiation programme and is the transcriptional activator of $P P A R \gamma$ and $C / E B P \alpha$. These in vitro data, however, do not unequivocally illustrate what might occur in vivo. Although several studies confirm our data regarding the upregulation of $P P A R \gamma$ during the anabolic course of lipid storage in HFD-fed mice ${ }^{(39)}$, a recent work by Soccio et al. ${ }^{(40)}$ with genomic experiments showed a reduced level of $P P A R \gamma$ and $P P A R \gamma$ DNA/chromatin occupancy in obese mice consistent with earlier reports ${ }^{(41)}$. In the attempt to interpret these apparently contrasting data, we can consider that $P P A R \gamma$ may perform different functions in metabolically sick rodents compared with healthy ones, as recently discussed by Bandera Merchan et al. ${ }^{(39)}$. Similarly, in healthy subjects, a HFD induces $P P A R \gamma$, whereas the same diet decreases $P P A R \gamma$ in morbidly obese patients $^{(42)}$. In our healthy mice fed the HFD, we also registered an increase in PPAR levels and, following the observations of the cited authors, it would be informative to study the levels of $P P A R \gamma$ in this model when the disease aggravates towards morbid obesity after longer periods on the HFD.

We just mentioned above that 7-HMR metabolites show higher efficiency in inhibiting cell differentiation in 3T3-L1 cells already at nm doses. However, knowing that metabolism of 7-HMR takes $24-48 \mathrm{~h}$ to be $95 \%$ complete, that $C_{\max }$ for ENL is reached at $24 \mathrm{~h}$ and that ENL appearance continues up

Table 3. Concentration of enterolactone and enterodiol in mouse serum* (Mean values and standard deviations; $n 16$ samples/group)

\begin{tabular}{|c|c|c|c|c|c|c|c|c|c|c|}
\hline & \multicolumn{2}{|c|}{ LFD } & \multicolumn{2}{|c|}{ HFD } & \multicolumn{3}{|c|}{ HFD plus 7-HMR } & \multicolumn{3}{|c|}{ HFD plus TEP } \\
\hline & Mean & SD & Mean & SD & Mean & SD & $P$ & Mean & SD & $P$ \\
\hline Enterolactone (ng/ml) (MW: 298.338) & \multicolumn{2}{|c|}{ ND } & 10 & 2.5 & 39 & 7 & 0.044 & 28 & 5 & 0.048 \\
\hline Enterodiol (ng/ml) (MW: 302.37) & 6 & $2 \cdot 9$ & 16 & 2.9 & 22 & 4 & 0.049 & 19 & 5 & \\
\hline
\end{tabular}

LFD, low-fat diet; HFD, high-fat diet; 7-HMR, 7-hydroxymatairesinol; TEP, total Picea abies extract; MW, molecular weight.

* Lignan metabolites were measured by HPLC-MS/MS in mouse serum. From the left column: control mice on the LFD, mice on the HFD, mice on the HFD plus 7-HMR; mice on the HFD plus TEP. $P=$ actual value. 
(a)

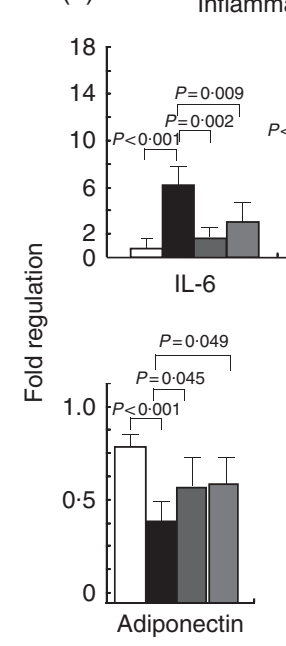

(c) Inflammation

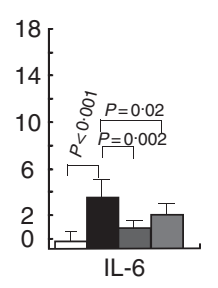

Epididymal fat

(b)

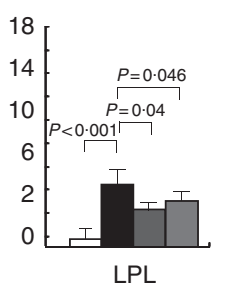

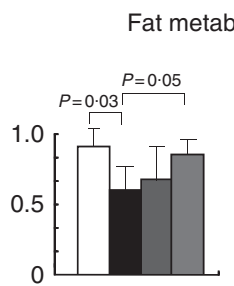

ATGL

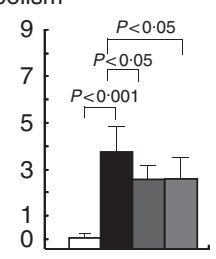

PLA2G7

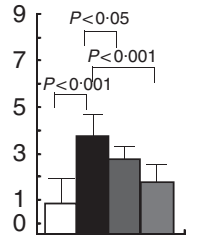

Leptin
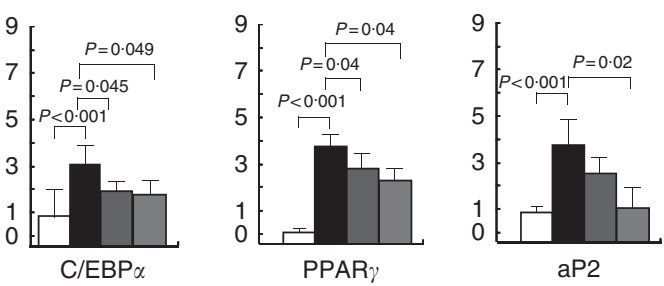

Liver

(d)

(e)

(f)

Lipid metabolism

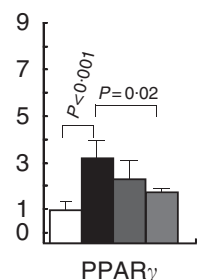

Fig. 5. Gene expression analysis in epididymal fat and the liver. The expression of a set of genes involved in (a), (c) inflammation and (b), (f) fat metabolism (d), antioxidant defences and (e) autophagy were quantified in epididymal fat and liver tissues of the treated mice. Values are mean fold change ( $n 8)$, with their standard errors represented by vertical bars. The experiments were performed by the use of Taqman LDA microfluidic cards with HPRT1 RNA used as the normalising gene. $\square$, Control; $\square$, high-fat diet (HFD); $\square$, HFD + 7-hydroxymatairesinol (7-HMR); $\square$, HFD + total Picea abies extract (TEP). $P=$ actual value or $P<0.001$.

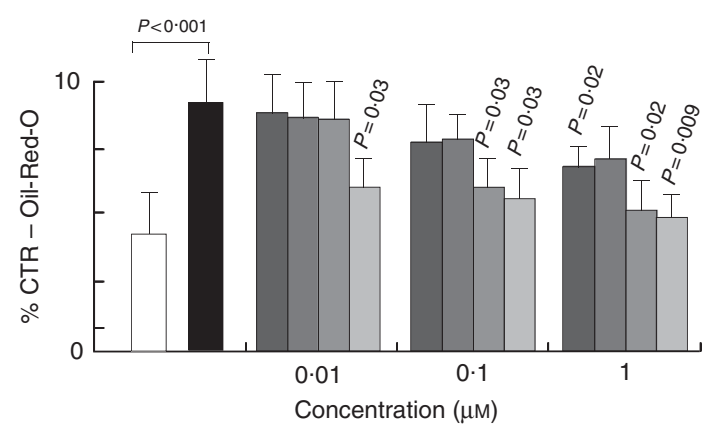

Fig. 6. Regulation of cell differentiation by lignin. 3T3-L1 cells were either maintained in undifferentiated (basal) or differentiated state (3-isobutyl-1methylxanthine, dexamethasone, insulin; MDI) and stimulated for $9 \mathrm{~d}$ with vehicle as control $(C)$. During MDI-induced differentiation the cells were treated with 7-hydroxymatairesinol (7-HMR), total Picea abies extract (TEP), enterolactone $(E N L)$ and enterodiol (END) at increasing concentrations $(0.01,0.1,1 \mu \mathrm{M})$. The effect of these compounds on cell differentiation was measured by the Oil-Red-O staining $9 \mathrm{~d}$ after transfection. Values were expressed as percentage of control undifferentiated and untreated (vehicle) cells. Differentiated cells $v$. control undifferentiated cells; 7-HMR, TEP, ENL, END v. MDI-treated cells. Values are means $(n 4)$, with their standard errors represented by vertical bars. $\square$, C; $\square$, MDI; $\square$, MDI + 7-hydroxymatairesinol (7-HMR); $\square$, MDI + TEP; $\square$, $\mathrm{MDI}+\mathrm{ENL} ; \square, \mathrm{MDI}+\mathrm{END}$. $P$ = actual value, compared with controls (cells in basal medium). $P=$ actual value or $P<0.001$ compared with controls (MDI-treated cells). to $72 \mathrm{~h}$ and more ${ }^{(16)}$, we also included 7-HMR and TEP in our in vitro experiments. The results show that unmodified 7-HMR was effective only at $1 \mu \mathrm{m}$, indicating that its metabolism is required for full biological activity and that in its unmodified form it only marginally contributes to the observed effects. Consistently with this, in HEPA cells a significant inhibition of TAG accumulation is achieved only by the metabolised lignans. In contrast, at the molecular level all the lignans were effective on the expression of $C / E B P \alpha$ and $a P 2$ in 3T3-L1 cells, probably indicating that other factors involved in the differentiation process are differentially targeted by the specific lignans ${ }^{(43)}$.

This represents the first comprehensive study of 7-HMR on metabolic functions altered by HFD at doses that can be reached through nutraceutical supplementation and dietary intake. The highest amount of 7-HMR can be assumed in a nutraceutical form. HMRLignan ${ }^{\mathrm{TM}}$ can provide an intake of about $2-3 \mathrm{mg} / \mathrm{kg}$, depending on the formulation $(36-144 \mathrm{mg} / \mathrm{d})^{(16,44)}$. 7-HMR is also the most abundant lignan in cereals and the dominant lignan in wheat, triticale, oat and millet bran (from 3 up to $7-9 \mathrm{mg}$ / $100 \mathrm{~g})^{(10)}$. It is present at a high concentration in sesame $(17 \mathrm{mg} /$ $100 \mathrm{~g})^{(45)}$, which is often consumed daily as sesame paste (tahin) in the Middle Eastern countries and it is widespread in several plants (i.e. $1.3 \mathrm{mg} / 100 \mathrm{~g}$ cranberry seeds) ${ }^{(45)}$. Consumption of a 
(a)

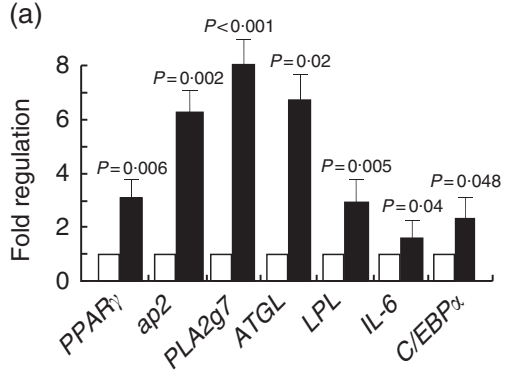

(b)

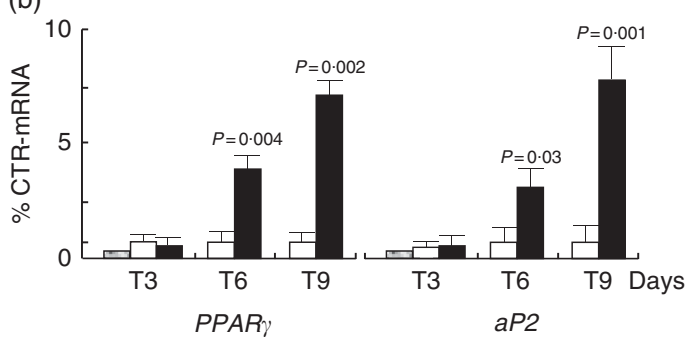

(b1)

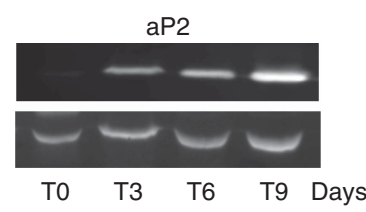

PPAR $\gamma$

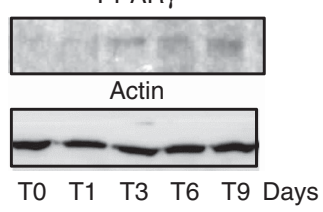

(c)

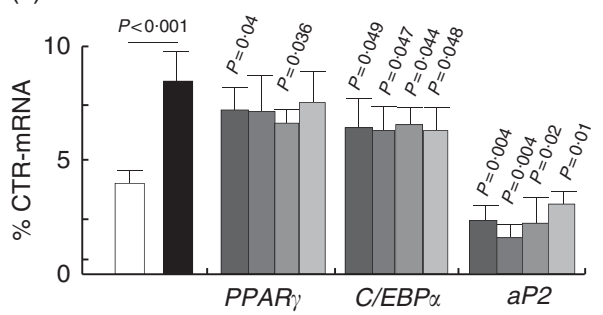

(c1) aP2

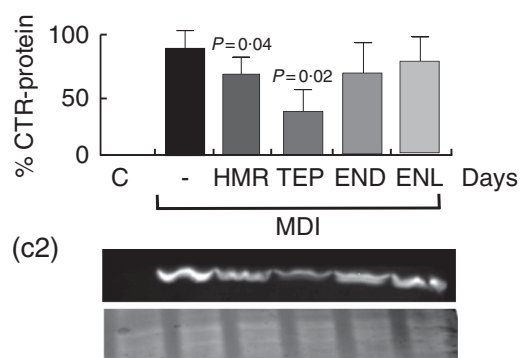

Fig. 7. Regulation of adipogenic factors in 3T3-L1 cells. (a) Regulation of genes of fat metabolism and inflammation in 3T3-L1 cells. Values are means ( $n$ 4), with their standard errors represented by vertical bars. $\square$, Control; $\mathbf{Q}$, MDI (3-isobutyl-1-methylxanthine, dexamethasone, insulin). $P=$ actual value, compared with controls (cells in basal medium). (b) Time course of PPARy and aP2 mRNA expression and protein synthesis in differentiating 3T3-L1 cells. 3T3-L1 cells were treated with MDI for 3,6 and $9 \mathrm{~d}$ and then mRNA and proteins were harvested for the measurement of PPARY and $a P 2 \mathrm{mRNA}$ and protein (b1) as molecular factors of cell differentiation. Data are shown as mean values of at least three experiments. Values are means $(n 3)$, with standard errors represented by vertical bars. $P=$ actual value, compared with controls (cells in basal medium). (c) Differentiating cells were treated for $9 \mathrm{~d}$ with vehicle as control (C) or 7-hydroxymatairesinol, total Picea abies extract (TEP), enterolactone and enterodiol at the active concentration of $1 \mu \mathrm{m}$ in the differentiation (MDI) medium. mRNA expression levels of PPARY, C/EBPa and aP2 mRNA and protein were evaluated by real-time RT-PCR. mRNA expression of control cells was arbitrarily set at 1. (c1) Densitometric scanning of aP2 protein level measured by Western blotting (c2). Values are means $(n 5)$, with their standard errors represented by vertical bars. $\square, \mathrm{C} ; \boldsymbol{\square}, \mathrm{MDI} ; \square, \mathrm{MDI}+7$-hydroxymatairesinol $(7-\mathrm{HMR}) ; \square, \mathrm{MDI}+\mathrm{TEP} ; \square, \mathrm{MDI}+\mathrm{ENL}$; $\square, \mathrm{MDI}+$ END. $P=$ actual value, compared with controls (cells in basal medium). $P=$ actual value, compared with controls (MDI-treated cells).

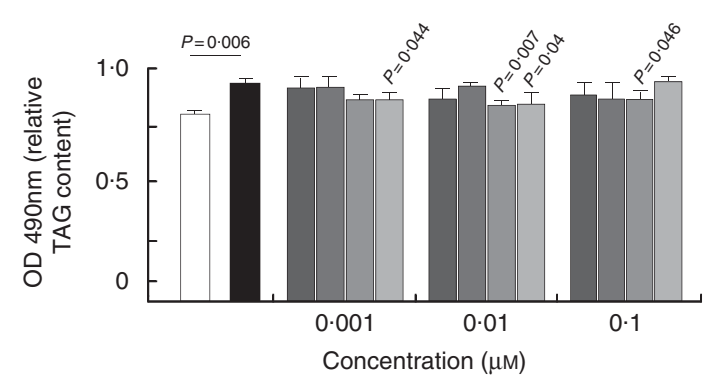

Fig. 8. Quantification of TAG in HEPA 1-6 hepatocytes. Cells were stimulated with palmitic acid alone (PA) or plus 7-hydroxymatairesinol (7-HMR), total Picea abies extract (TEP), enterolactone (ENL) and enterodiol (END) in the concentration range of $0.001,0.01$ and $0.1 \mu \mathrm{m}$ for $24 \mathrm{~h}$ and the accumulated TAG were measured by the Oil-Red-O assay. Values are means of six experiments ( $n 12$ per dose), with their standard errors represented by vertical bars. $\square$, Control; $\square$, PA; $\square$, PA + 7-HMR; $\square$, PA + TEP; $\square$, PA+END; $\square$, $\mathrm{PA}+\mathrm{ENL}$. PA-treated cells $v$. control untreated cells, $P=$ actual value.

diet rich in these foods may bring 7-HMR daily intake to as much as $30 \mathrm{mg} / \mathrm{d}$, very close to nutraceutical doses. Moreover, the ENL levels $(39 \mathrm{ng} / \mathrm{ml})$ reached in plasma of our mice treated with
$3 \mathrm{mg} / \mathrm{kg}$ of $7-\mathrm{HMR}$ are quite close to the concentration of ENL that can be found in people consuming conventional northern European diets $(14.8 \text { and } 12 \mathrm{ng} / \mathrm{ml})^{(20,46)}$ and lignan-fortified diets $(21 \mathrm{ng} / \mathrm{ml})^{(47)}$, but we can realistically hypothesise that it can be found at a higher concentration in people consuming lignan-richer diets with the food components cited above (i.e. Middle Eastern or Mediterranean diets) ${ }^{(48)}$.

In conclusion, this work adds novel information to what has been found for other lignans in similar models ${ }^{(4,13,49,50)}$ and highlights the physiological relevance of 7-HMR from nutraceutical and nutritional sources.

\section{Acknowledgements}

The authors thank Stephanie Hodeib for English writing and Alessandro Bulla for editing assistance. The authors thank Moris Cadei for histochemical analysis.

This work was supported in part by European Union Grants QLK4-CT-2002-02221 (EDERA) and LSHB-CT-2006-037168 (EXERA), Fondo Ex.60\% (G. B. and I. Z.) of the University of Brescia. 
G. B. and I. Z. performed animal treatments, autopsy, tissue collection, detailed experimental design, Echo MRI analysis and in vitro assays (3T3-L1, HEPA6 cells). F. P. performed tissue extraction and qRNA analysis, gene expression analysis and in vitro assays (3T3-L1). M. C. performed histology. I. A. carried out blood collection from the mice, analysis of biochemical parameters, monitoring of animal health and animal care and quantification of food and water consumption. M. L. and B. P. contributed to preparation of chemicals to be administered, title and analytical control of chemical purity and performed quality control. E. M. carried out adipocytic differentiation in vitro and gene expression profiles from cell cultures (3T3-L1). P. M. and R. A. carried out cell culture maintenance; animal maintenance, care, feeding and control; and DNA extraction and amplification. (Moreover, they performed HPLC and MS analysis on several markers that, although not present in this article, greatly contribute to understand the efficiency of the studied chemicals.) G. D. P. performed data analysis, linearity, accuracy and precision, and contributed in writing the paper for his part of competence. F. S. carried out statistical analysis of the in vivo experiments and contributed to writing the paper for his part of competence. A. S. performed determination of 7-HMR and metabolites in mouse serum. D. D. L. contributed to study conception and design, data analysis and in writing the paper.

Two scientists from the company that manufactures and markets the studied chemicals contributed to this work (M. L. and B. P., Linnea SA).

\section{References}

1. Shamseddeen H, Getty JZ, Hamdallah IN, et al. (2011) Epidemiology and economic impact of obesity and type 2 diabetes. Surg Clin North Am 91, 1163-1172.

2. Keaver L, Webber L, Dee A, et al. (2013) Application of the UK foresight obesity model in Ireland: the health and economic consequences of projected obesity trends in Ireland. PLOS ONE 8, e79827.

3. Poyrazoglu S, Bas F \& Darendeliler F (2014) Metabolic syndrome in young people. Curr Opin Endocrinol Diabetes Obes 21, 56-63.

4. Brown L, Poudyal H \& Panchal SK (2015) Functional foods as potential therapeutic options for metabolic syndrome. Obes Rev 16, 914-941.

5. Milder IE, Kuijsten A, Arts IC, et al. (2007) Relation between plasma enterodiol and enterolactone and dietary intake of lignans in a Dutch endoscopy-based population. J Nutr 137, $1266-1271$

6. Ayres CD \& Loike DJ (1990) Lignans: Chemical, Biological and Clinical Properties. Cambridge: Cambridge University Press.

7. Namiki M (2007) Nutraceutical functions of sesame: a review. Crit Rev Food Sci Nutr 47, 651-673.

8. Kamal-Eldin A, Moazzami A \& Washi S (2011) Sesame seed lignans: potent physiological modulators and possible ingredients in functional foods \& nutraceuticals. Recent Pat Food Nutr Agric 3, 17-29.

9. Muir AD (2006) Flax lignans - analytical methods and how they influence our understanding of biological activity. J AOAC Int 89, 1147-1157.
10. Smeds AI, Eklund PC, Sjöholm RE, et al. (2007) Quantification of a broad spectrum of lignans in cereals, oilseeds, and nuts. J Agric Food Chem 55, 1337-1346.

11. Kuhnle GG, Dell'Aquila C, Aspinall SM, et al. (2008) Phytoestrogen content of beverages, nuts, seeds, and oils. J Agric Food Chem 56, 7311-7315.

12. Hovelstad H, Leirset I, Oyaas K, et al. (2006) Screening analyses of pinosylvin stilbenes, resin acids and lignans in Norwegian conifers. Molecule 11, 103-114.

13. Biasiotto G, Penza M, Zanella I, et al. (2014) Oilseeds ameliorate metabolic parameters in male mice, while contained lignans inhibit 3T3-L1 adipocyte differentiation in vitro. EurJ Nutr 53, 1685-1697.

14. Smeds AI, Jauhiainen L, Tuomola E, et al. (2009) Characterization of variation in the lignan content and composition of winter rye, spring wheat, and spring oat. Agric Food Chem 57, $5837-5842$

15. Saarinen NM, Wärri A, Mäkelä SI, et al. (2000) Hydroxymatairesinol, a novel enterolacton eprecursor with antitumor properties from coniferous tree (Picea abies). Nutr Cancer 36, 207-216.

16. Udani JK, Brown DJ, Tan MO, et al. (2013) Pharmacokinetics and bioavailability of plant lignan 7-hydroxymatairesinol and effects on serum enterolactone and clinical symptoms in postmenopausal women: a single-blinded, parallel, dosecomparison study. J Am Coll Nutr 32, 428-435.

17. Dar AA \& Arumugam N (2013) Lignans of sesame: purification methods, biological activities and biosynthesis - a review. Bioorg Chem 50, 1-10.

18. Mukker JK, Kotlyarova V, Singh RS, et al. (2010) HPLC method with fluorescence detection for the quantitative determination of flaxseed lignans. J Chromatogr B Analyt Technol Biomed Life Sci 878, 3076-3082.

19. Abdollahi M, Salehnia A, Mortazavi SH, et al. (2003) Antioxidant, antidiabetic, antihyperlipidemic, reproduction stimulatory properties and safety of essential oil of Satureja khuzestanica in rat in vivo: a toxicopharmacological study. Med Sci Monit 9, BR331-BR335.

20. Smeds A \& Hakala K (2003) Liquid chromatographictandem mass spectrometric method for the plant lignan 7-hydroxymatairesinol and its potential metabolites in human plasma. J Chromatogr B Analyt Technol Biomed Life Sci 793, 297-308.

21. Smeds AI, Hakala K, Hurmerinta TT, et al. (2006) Determination of plant and enterolignans in human serum by high-performance liquid chromatography with tandem mass spectrometric detection. I Pharm Biomed Anal 41, 898-905.

22. Zanella I, Marrazzo E, Biasiotto G, et al. (2015) Soy and the soy isoflavone genistein promote adipose tissue development in male mice on a low fat diet. Eur J Nutr 54, 1095-1107.

23. Lin B, Koibuchi N, Hasegawa Y, et al. (2014) Glycemic control with empagliflozin, a novel selective SGLT2 inhibitor, ameliorates cardiovascular injury and cognitive dysfunction in obese and type 2 diabetic mice. Cardiovasc Diabetol 13, 14.

24. Zanella I, Derosas M, Corrado M, , et al. (2008) The effects of frataxin silencing in HeLa cells are rescued by the expression of human mitochondrial ferritin. Biochim Biophys Acta $\mathbf{1 7 8 2}$, 90-98.

25. Biasiotto G, Zanella I, Masserdotti A, et al. (2016) Municipal wastewater affects adipose deposition in male mice and increases 3T3-L1 cell differentiation. Toxicol Appl Pharmacol 297, 32-40.

26. Cocco E, Porrini V, Derosas M, et al. (2013) Protective effect of mitochondrial ferritin on cytosolic iron dysregulation 
induced by doxorubicin in HeLa cells. Mol Biol Rep $\mathbf{4 0}$, 6757-6764.

27. Xu C, Liu Q, Zhang Q, et al. (2015) Urinary enterolactone is associated with obesity and metabolic alteration in men in the US National Health and Nutrition Examination Survey 2001-10. Br J Nutr 113, 683-690.

28. O'Neill S, Bohl M, Gregersen S, et al. (2016) Blood-based biomarkers for metabolic syndrome. Trends Endocrinol Metab 27, 363-374.

29. Smith BK, Andrews PK \& West DB (2000) Macronutrient diet selection in thirteen mouse strains. Am J Physiol Regul Integr Comp Physiol 278, R797-R805.

30. West DB, Boozer CN, Moody DL, et al. (1992) Dietary obesity in nine inbred mouse strains. Am J Physiol 262, R1025-R1032.

31. Ha SK \& Chae C (2010) Inducible nitric oxide distribution in the fatty liver of a mouse with high fat diet-induced obesity. Exp Anim 59, 595-604

32. Yue F, Cheng Y, Breschi A, et al. (2014) A comparative encyclopedia of DNA elements in the mouse genome. Nature $\mathbf{5 1 5}, 355-364$.

33. Rosen ED (2005) The transcriptional basis of adipocyte development. Prostaglandins Leukot Essent Fatty Acids 73, 31-34.

34. Bolsoni-Lopes A \& Alonso-Vale MI (2015) Lipolysis and lipases in white adipose tissue - an update. Arch Endocrinol Metab 59, 335-342.

35. MacDougald OA \& Lane MD (1995) Transcriptional regulation of gene expression during adipocyte differentiation. Annu Rev Biochem 64, 345-373.

36. Settembre C, De Cegli R, Mansueto G, et al. (2013) TFEB controls cellular lipid metabolism through a starvationinduced autoregulatory loop. Nat Cell Biol 15, 647-658.

37. Li X, Huang HY, Chen JG, et al. (2006) Lactacystin inhibits 3T3L1 adipocyte differentiation through induction of CHOP-10 expression. Biochem Biophys Res Commun 350, 1-6.

38. Batchvarova N, Wang XZ \& Ron D (1995) Inhibition of adipogenesis by the stress-induced protein CHOP (Gadd153). EMBO J 14, 4654-4661.

39. Bandera Merchan B, Tinahones FJ \& Macías-González M (2016) Commonalities in the association between PPAR $\gamma$ and vitamin $\mathrm{D}$ related with obesity and carcinogenesis. PPAR Res 2016, 2308249.

40. Soccio RE, Li Z, Chen ER, et al. (2017) Targeting PPAR $\gamma$ in the epigenome rescues genetic metabolic defects in mice. $J$ Clin Invest 127, 1451-1462

41. Pedersen DJ, Guilherme A, Danai LV, et al. (2015) A major role of insulin in promoting obesity-associated adipose tissue inflammation. Mol Metab 4, 507-518.

42. Garcia-Fuentes E, Murri M, Garrido-Sanchez L, et al. (2010) PPAR $\gamma$ expression after a high-fat meal is associated with plasma superoxide dismutase activity in morbidly obese persons. Obesity 18, 952-958.

43. Kim E, Kim EJ, Seo SW, et al. (2014) Meta-review of protein network regulating obesity between validated obesity candidate genes in the white adipose tissue of high-fat diet-induced obese C57BL/6J mice. Crit Rev Food Sci Nutr 54, 910-923.

44. Cosentino M, Marino F \& Pacchetti B (2018) Effect of the food supplement HMR lignan on lipid and glucose metabolism in overweight and obese patients: a randomized, double-blind, placebo-controlled study (In the Press).

45. Smeds AI, Eklund PC \& Willför SM (2012) Content, composition, and stereochemical characterisation of lignans in berries and seeds. Food Chem 134, 1991-1998.

46. Bolvig AK, Kyrø C, Nørskov NP, et al. (2016) Olsen use of antibiotics is associated with lower enterolactone plasma concentration. Mol Nutr Food Res 60, 2712-2721.

47. Vanharanta M, Mursu J, Nurmi T, et al. (2002) Fortification in rye bread elevates serum enterolactone level. Eur J Clin Nutr 56, 952-957.

48. Zanella I, Biasiotto G, Holm F, et al. (2017) Cereal's lignan, natural compounds of interest for human health? Nat Prod Commun 12, 139-146.

49. Imran M, Ahmad N, Anjum FM, et al. (2015) Potential protective properties of flax lignan secoisolariciresinol diglucoside. Nutr J 14, 71-79.

50. Adolphe JL, Whiting SJ, Juurlink BH, et al. (2010) Health effects with consumption of the flax lignan secoisolariciresinol diglucoside. Br J Nutr 103, 929-938. 